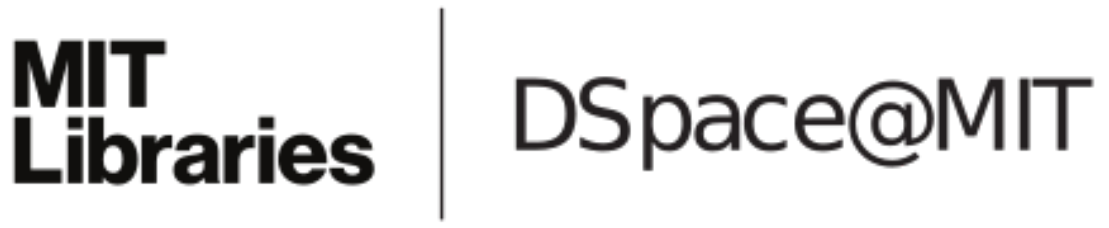

\author{
MIT Open Access Articles
}

Dynamical and thermodynamical analysis

of the South China Sea winter cold tongue

The MIT Faculty has made this article openly available. Please share how this access benefits you. Your story matters.

Citation: Thompson, Bijoy et al. "Dynamical and Thermodynamical Analysis of the South China Sea Winter Cold Tongue." Climate Dynamics 47.5-6 (2016): 1629-1646.

As Published: http://dx.doi.org/10.1007/s00382-015-2924-3

Publisher: Springer Berlin Heidelberg

Persistent URL: http://hdl.handle.net/1721.1/104785

Version: Author's final manuscript: final author's manuscript post peer review, without publisher's formatting or copy editing

Terms of use: Creative Commons Attribution-Noncommercial-Share Alike 


\title{
Dynamical and thermodynamical analysis of the South China Sea winter cold tongue
}

\author{
Bijoy Thompson $^{1} \cdot$ Pavel Tkalich $^{1} \cdot$ Paola Malanotte-Rizzoli $^{2} \cdot$ Bastien Fricot $^{3} \cdot$ \\ Juliette Mas $^{3}$
}

Received: 24 July 2015 / Accepted: 16 November 2015

(C) Springer-Verlag Berlin Heidelberg 2015

\begin{abstract}
Spatial distribution of the South China Sea (SCS) surface temperature shows strong cold anomalies over the Sunda Shelf during the boreal winter season. The band of low sea surface temperature (SST) region located south/southeast of Vietnam is called as the winter cold tongue (CT) in the SCS. Using observational and re-analysis datasets a comprehensive investigation of the dynamical and thermodynamical processes associated with the evolution of SCS CT is performed in this study. The role and relative importance of wind-driven ocean transports, air-sea heat fluxes and oceanic processes are explored. The north-south Sverdrup transport demonstrates strong southward transport during the northeast monsoon period aiding the SST cooling by bringing relatively cold water from the north. The zonal and meridional Ekman transports exhibit relatively weak westward and northward transports to the $\mathrm{CT}$ region during this period. The study suggests that winddriven ocean transports have a significant role in regulating the shape and spatial extent of the CT. The heat budget analysis revealed that net surface heat flux decrease during the northeast monsoon acts as the primary cooling mechanism responsible for the development of the SCS CT, while the horizontal advection of cold water by the western boundary current along the coast of Vietnam plays a secondary role. The wintertime SST anomalies over the CT
\end{abstract}

Bijoy Thompson

bijoymet@gmail.com

1 Tropical Marine Science Institute, National University of Singapore, Singapore 119222, Singapore

2 Department of Earth, Atmospheric and Planetary Sciences, Massachusetts Institute of Technology, Cambridge, MA 02139, USA

3 French Naval Academy, 29240 Brest, France region are significantly linked to the Nino3 index. Most of the warming/cooling events in the SST anomalies coincide with the El Nino/La Nina phenomena in the Pacific Ocean.

Keywords South China Sea $\cdot$ Cold tongue $\cdot$ Wind-driven transport $\cdot$ Heat budget

\section{Introduction}

Sea surface temperature (SST) over the South China Sea (SCS) has an important role in regulating the weather and climate of the Southeast Asian region in various time scales ranging from diurnal, seasonal and inter-annual (Shen and Lau 1995; Liu and Xie 1999; Qu et al. 2005; Varikoden et al. 2010; Koseki et al. 2013; Liu et al. 2014). The surface circulation and temperature over the SCS exhibit a strong seasonal cycle subjected to the influence of monsoons (Wyrtki 1961). Surface winds over the SCS are southwesterly during the southwest/summer monsoon period (JuneSeptember) while relatively strong northeasterly winds prevails in the northeast/winter monsoon (November-February). Seasonal reversal of the winds leads to a basin-wide cyclonic and anticyclonic upper layer circulation pattern in the SCS during the northeast and southwest monsoons respectively (Wyrtki 1961). The seasonal variability of the SCS surface temperature is larger $\left(>6^{\circ} \mathrm{C}\right)$ in the north and relatively weaker $\left(<4{ }^{\circ} \mathrm{C}\right)$ in the equatorial region $(\mathrm{Qu}$ 2001; Chen et al. 2003). In the spatial distribution of annual mean SST, the isotherms mainly have a southwest to northeast orientation (Chu et al. 1997; Qu 2001). In general, the SCS SST is warmer $\left(>28^{\circ} \mathrm{C}\right)$ during mid spring to early fall (April-October) and cooler $\left(<28^{\circ} \mathrm{C}\right)$ from late fall to early spring (November-March) seasons. 
Fig. 1 Bathymetry of the South China Sea. The blue colored box represents the study domain. The SCS CT region is indicated by the inner box. Depth of water above $50 \mathrm{~m}$ is shaded in the figure

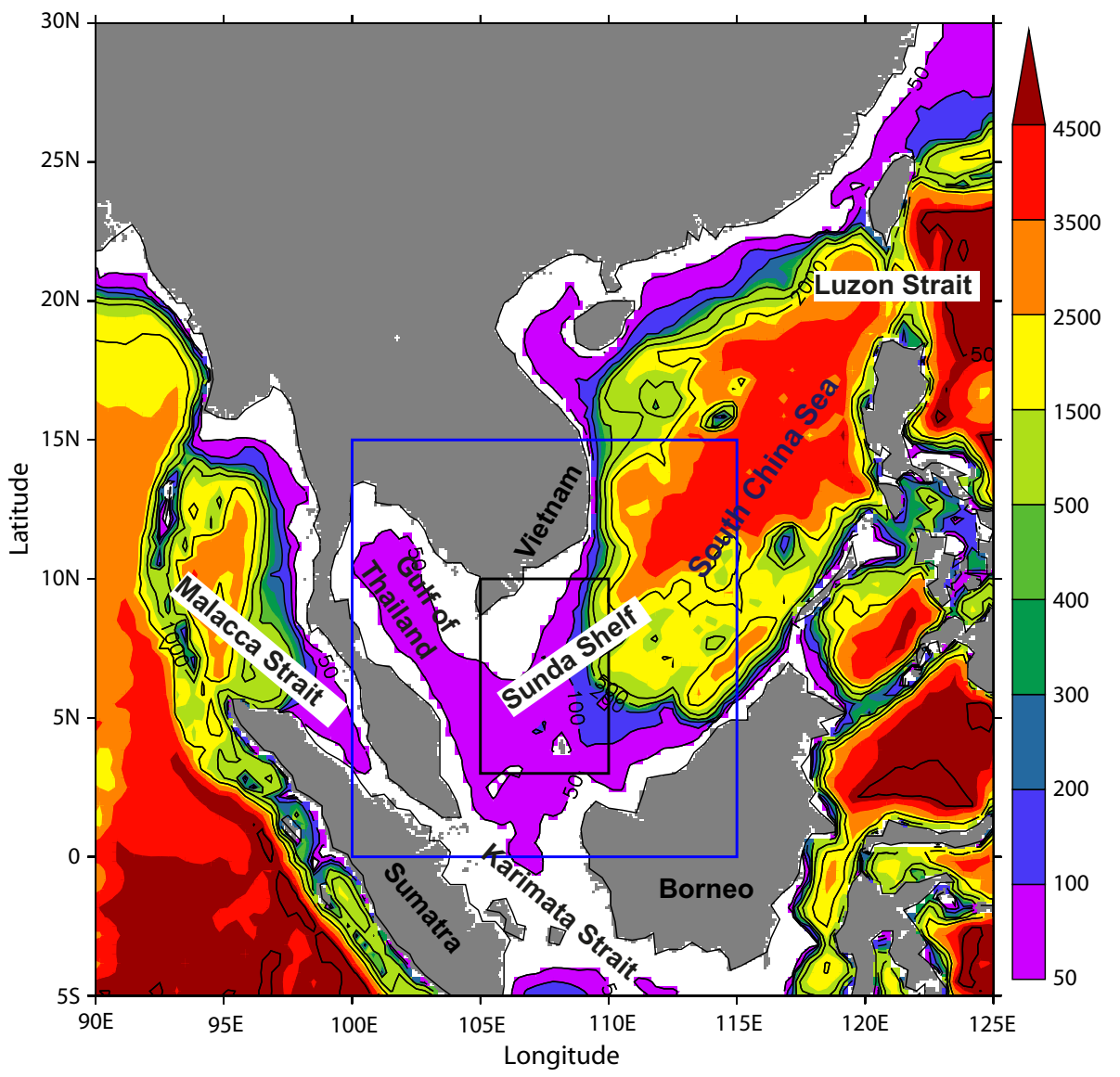

The tropical eastern Indian and western Pacific Oceans comprise a broad area of warm surface waters, where the SST is generally greater than $28{ }^{\circ} \mathrm{C}$, known as the IndoPacific warm pool. Both in the regional and global scales this warm pool region has great climatic importance and is characterized by frequent convective storms. Energy released by the convective storms is considered as the primary energy source for the global circulation system $(\mathrm{Qu}$ et al. 2005). Geographically, the SCS is located between the Indian and Pacific Oceans and connected to these oceans through a number of straits (Fig. 1). The key bathymetric features and major passages for water exchange to the SCS from the Pacific and Indian Oceans are shown in the figure. In the south, the SCS is occupied with one of the largest sea-shelves called the Sunda Shelf where the depth of water varies from 40 to $100 \mathrm{~m}$ while moving towards the central SCS. Due to its location in the middle of the Indo-Pacific warm pool, SST over the SCS and Indonesian Seas have significant influence on the convective activities and hence the precipitation distribution (Qu et al. 2005). A study by Liu et al. (2004) revealed the presence of a band of low SST $\left(<26{ }^{\circ} \mathrm{C}\right)$ in the middle of southern SCS during winter. This low SST region is often called as the winter cold tongue (CT) in the SCS. This cold water penetrates further south of the SCS leading to a noticeable gap in the Indo-Pacific warm pool. Southward advection of cold water by strong western boundary current along the Vietnam coast is considered as the main factor responsible for the formation of this cold tongue (Liu et al. 2004; Varikoden et al. 2010).

The SST CT is an important element in the seasonal and inter-annual variations of the SCS climate (Liu et al. 2004). Inter-annual variability of the CT is considered as a measure to monitor the changes in East Asian northeast monsoon (Huang et al. 2011). Recent studies suggested that the SCS CT plays an active role in determining the winter monsoon characteristics over the Maritime Continent (e.g., Varikoden et al. 2010; Koseki et al. 2013). A modeling study by Koseki et al. (2013) revealed that the downstream of a strong CT is noted by the presence of an intensified monsoon. Further, they suggested that the CT affects diurnal cycle of wind and precipitation over the Maritime Continent. Hence, in order to improve predictions of rainfall variability, the oceanic as well as air-sea coupled processes controlling the SST variability need to be understood. However, despite its vital role in shaping/modifying the weather and climate over the Maritime Continent, studies addressing the role as well as relative importance of 
atmospheric forcing, air-sea interaction and ocean dynamics on the evolution of SCS CT are very limited in the literature. Thus, one of the main objectives of this study is to present a comprehensive analysis on the development of the SCS CT and related ocean-atmospheric processes.

First, based on SST observations, a brief description on the evolution of $\mathrm{CT}$ is presented. Following the classical formation by Stommel (1965), the wind-driven ocean transports are computed and their association with the development of CT are discussed. The ocean mixed layer averaged temperature is often considered as a proxy for the SST (e.g., de Boyer et al. 2007; Thompson and Tkalich 2014). Heat budget analysis of the mixed layer temperature has been performed to understand the various physical processes contributing to the SST variations. The role of ocean dynamics and air-sea heat fluxes are then investigated. Temperature, salinity and current fields from the Simple Ocean Data Assimilation re-analysis and air-sea heat fluxes from National Oceanographic Centre are employed in the heat budget analysis. Further, the inter-annual variability of the SCS CT and its association with wind-driven ocean transports and mixed layer heat budget terms are also explored.

\section{Data}

The in situ observations of ocean temperature and surface heat fluxes over the SCS are relatively sparse compared with adjacent eastern Indian and western Pacific Oceans. In this context, the re-analysis datasets provide immense opportunity to understand the thermodynamics and dynamics of oceans where observations are limited. Here we have used satellite observations as well as the atmospheric and ocean re-analysis datasets from different sources to understand the evolution and dynamics of the SCS CT. Datasets such as the National Oceanographic and Atmospheric Administration (NOAA) daily SST observation, geostrophic currents obtained from Ssalto/Ducas multimission altimeter data products, European Centre for MediumRange Weather Forecasts Re-Analysis ocean surface wind fields, oceanic parameters from Simple Ocean Data Assimilation and National Oceanography Centre surface heat flux are used in the analysis. A brief discussion on different datasets used in the study is provided in this section.

For the observational analysis of SST, the NOAA daily Optimum Interpolation Sea Surface Temperature (AVHRR OISSTv2) is employed. The data is available in $0.25^{\circ} \times 0.25^{\circ}$ horizontal resolution. The data product is constructed by combining observations from different platforms, including the ships, buoys and Advanced Very High Resolution Radiometer (AVHRR) infrared satellite data, on a regular global grid (Reynolds et al. 2007). As satellite observations, the product uses Pathfinder AVHRR data from September 1981 to December 2005 and operational AVHRR data from 2006 onwards. The dataset is freely available at the website http://iridl.ldeo.columbia.edu/ SOURCES/.NOAA/.NCDC/.OISST/.version2/.AVHRR.

The wind-driven ocean transports are computed using the zonal and meridional wind fields from the European Centre for Medium-Range Weather Forecasts Re-Analysis (ERA-interim) dataset. The ERA-Interim is a global atmospheric re-analysis started in 1979 and updated in real time. The data assimilation procedure includes a 4-dimensional variational analysis with a $12 \mathrm{~h}$ analysis window. The spatial resolution of the data set is approximately $80 \mathrm{~km}$ (Dee et al. 2011).

The ocean temperature, salinity and current fields derived from Simple Ocean Data Assimilation (SODA) version 2.2.4 is employed in the heat budget analysis of the SCS CT. SODA v2.2.4 is a data assimilation product spanning over a period from 1871 to 2008 . The oceanic variables used in the assimilation are simulated using the general circulation model based on Parallel Ocean Program numerics with an average horizontal resolution of $0.25^{\circ} \times 0.4^{\circ}$ and 40 vertical layers. Assimilation of temperature and salinity observations from hydrographic profiles, ocean station data, moored measurements and a variety of instruments (e.g., MBT, XBT, CTD) are performed. The SST and sea level observations from satellites are also included in the assimilation system (Carton and Giese 2008). The ocean variables remapped to a uniform horizontal grid with $0.5^{\circ} \times 0.5^{\circ}$ horizontal resolution and 40 vertical levels is available to the users. SODA data from 1950 to 2008 are used in the present study.

The ocean surface heat flux components for the heat budget analysis are obtained from the National Oceanography Centre (NOC) flux dataset v2.0 (Berry and Kent 2009, 2011). NOC flux data provides latent heat flux, sensible heat flux, net longwave and shortwave radiation on a $1^{\circ}$ monthly mean grid for the global ice-free ocean. The flux estimates are obtained from in situ observations, estimates from satellites data, and numerical models values. The observations used to build this dataset come from the International Comprehensive Ocean Atmosphere Data. Though the flux data is available from 1973 to 2014, for consistency with SODA, the data during 1973-2008 period is employed in the analysis.

\section{Methodology}

\subsection{Wind-driven ocean transports}

Though the wind-driven transports are limited to the surface layers, it has profound significance in determining the 
ocean heat balance both in regional and global scales (Price et al. 1987; Alexander and Scott 2008). A major fraction of heat transport in the tropical oceans is contributed by the wind-driven Ekman transport (Levitus 1987). The winddriven transport is largely limited to the thin upper layers of the ocean. Observational studies have revealed that almost $95 \%$ of this transport occurs within the top $25 \mathrm{~m}$ of the ocean (e.g., Price et al. 1987). The strong monsoon winds, low value of Coriolis parameter due to its proximity to the equator and strong horizontal temperature gradients in the SCS emphasize the role of wind-driven transports in determining its internal temperature re-distribution.

According to Stommel (1965), the wind-driven ocean transports are estimated from the surface wind stress fields as:

The Meridional Ekman transport per unit width, $M E k T=-\tau_{x} /(\rho f)$

The Zonal Ekman transport per unit width, ZEkT $=\tau_{y}$ ' $(\rho f)$

The vertically integrated north-south geostrophic and Ekman transports per unit width or Sverdrup transport, $\operatorname{SvT}=\operatorname{curl}_{z} \tau /(\rho \beta)$

Here, $\tau_{x}$ and $\tau_{y}$ are zonal and meridional wind stress components which are computed ${ }_{2}$ using the bulk aerodynamic formulae, $\tau=\left(\tau_{x}^{2}+\tau_{y}^{2}\right)^{1 / 2}$ is the wind stress magnitude and $\rho=1025 \mathrm{~kg} / \mathrm{m}^{3}$, is the sea water density.

The Coriolis parameter, $f=2 \Omega \sin \phi$. Here, $\phi$ is the latitude and $\Omega=7.29 \times 10^{-5} \mathrm{rad} / \mathrm{sec}$ is the rotation rate of the earth.

The rate of change of the Coriolis parameter with latitude, $\beta=2 \Omega \cos (\phi / R)$, where $R=6.37 \times 10^{6} \mathrm{~m}$ is the average radius of the earth.

The displacement of water due to the wind-driven Ekman currents results in vertical motion into or out of the Ekman layer. According to Stommel (1965), the wind stress curl vertical velocity per unit area at the bottom of the Ekman layer is computed as;

$W_{E}=(1 / \rho f)\left(\operatorname{curl}_{z} \tau+\beta \tau_{x} / f\right)$.

Here $\operatorname{curl}_{z} \tau$ is the vertical component of wind stress curl and it is computed as

$\operatorname{curl}_{z} \tau=\partial \tau_{y} / \partial x-\partial \tau_{x} / \partial y$.

\subsection{Mixed layer heat budget}

One of the focuses of this study is to evaluate the role of oceanic processes and atmospheric forcing in shaping the seasonal cycle of SST over the SCS CT. The vertically averaged temperature tendency terms within a time varying mixed layer is computed using a mixed layer heat budget formulation (e.g. Vialard and Delecluse 1998; Thompson and Tkalich 2014). The depth of mixed layer is computed using a variable density criterion. The mixed layer depth
(MLD) is defined as the depth where the density increase corresponds to a temperature decrease of $0.5{ }^{\circ} \mathrm{C}$ from the surface. Here, the MLD is estimated from the surface and subsurface temperature and salinity obtained from the SODA data. The mixed layer temperature tendency is computed as:

Mixed layer temperature tendency, $\partial_{t} T_{m l d}=\left[Q_{f x}\right]+\left[Q_{h a d v}\right]+\left[Q_{\text {vert-process }}\right]+R_{\text {res }}$, where $Q_{f l x}$ is the net surface heat flux, $Q_{h a d v}$ is the sum of zonal and meridional advections, $Q_{\text {vert-process }}$ is the sum of vertical advection ansd vertical diffusion, and $R_{\text {res }}$ is the residual term for the unaccounted effects.

$$
\begin{aligned}
\partial_{t} T_{m l d}= & {\left[\frac{\left(Q *+Q_{s}\left(1-f_{(h)}\right)\right)}{\rho C_{p} h}\right] } \\
& -\left[\frac{1}{h}\left(\int_{0}^{h} u \cdot \partial_{x} T_{m l d} \cdot \mathrm{dz}+\int_{0}^{h} v \cdot \partial_{y} T_{m l d} \cdot \mathrm{dz}\right)\right] \\
& +\left[\frac{1}{h}\left(\frac{\mathrm{dh}}{\mathrm{dt}}+w_{(h)}\right)\left(T_{m l d}-T_{(h)}\right)+\frac{\left(K \partial_{z} T\right)_{(h)}}{h}\right]+R_{r e s},
\end{aligned}
$$

Where, $h \sim$ mixed layer depth, $Q^{*}$ and $Q_{S} \sim$ non solar and solar components of heat flux, $T \sim$ water temperature, $T_{m l d} \sim$ mixed layer averaged temperature, $T_{h} \sim$ temperature at the bottom of mixed layer, $W_{(H)} \sim$ vertical velocity at the bottom of mixed layer, $K \sim$ vertical diffusion coefficient $t, C_{p}=4000 \mathrm{~J} / \mathrm{kg} / \mathrm{K}$, is the specific heat capacity of sea water, and fraction of short wave flux reaches the depth $h, f_{(h)}=\operatorname{Re}^{-\left(h / l_{1}\right)}+(1-R) e^{-\left(h / l_{2}\right)}$. Here the attunation coefficients are selected for a type I water (Jerlov 1968), $R=0.58, l_{1}=0.35 \mathrm{~m}$, and $l_{2}=23 \mathrm{~m}$.

\section{Results and discussion}

\subsection{Evolution of the SCS cold tongue}

The evolution of the winter cold tongue is investigated using the daily SST climatology computed from OISSTv2 data for the 1982-2012 period. The spatial distribution of daily SST climatology over the southern SCS during the months from November to March is shown in Fig. 2. The CT region is distinguished as the region of water where the temperature is less than $28{ }^{\circ} \mathrm{C}$ in the figure (indicated by the contours). During early November, SST over most of the southern and central SCS is greater than $28{ }^{\circ} \mathrm{C}$. The CT originates with the onset of northeast monsoon in November along the east coast of Vietnam. Gradually, the CT region extends continuously southwestwards and covers most of the Sunda Shelf, except the Gulf of Thailand, by mid-December. Subsequently a rapid drop in SST is noted till early February. The $\mathrm{CT}$ reaches its maximal spreading and minimal 


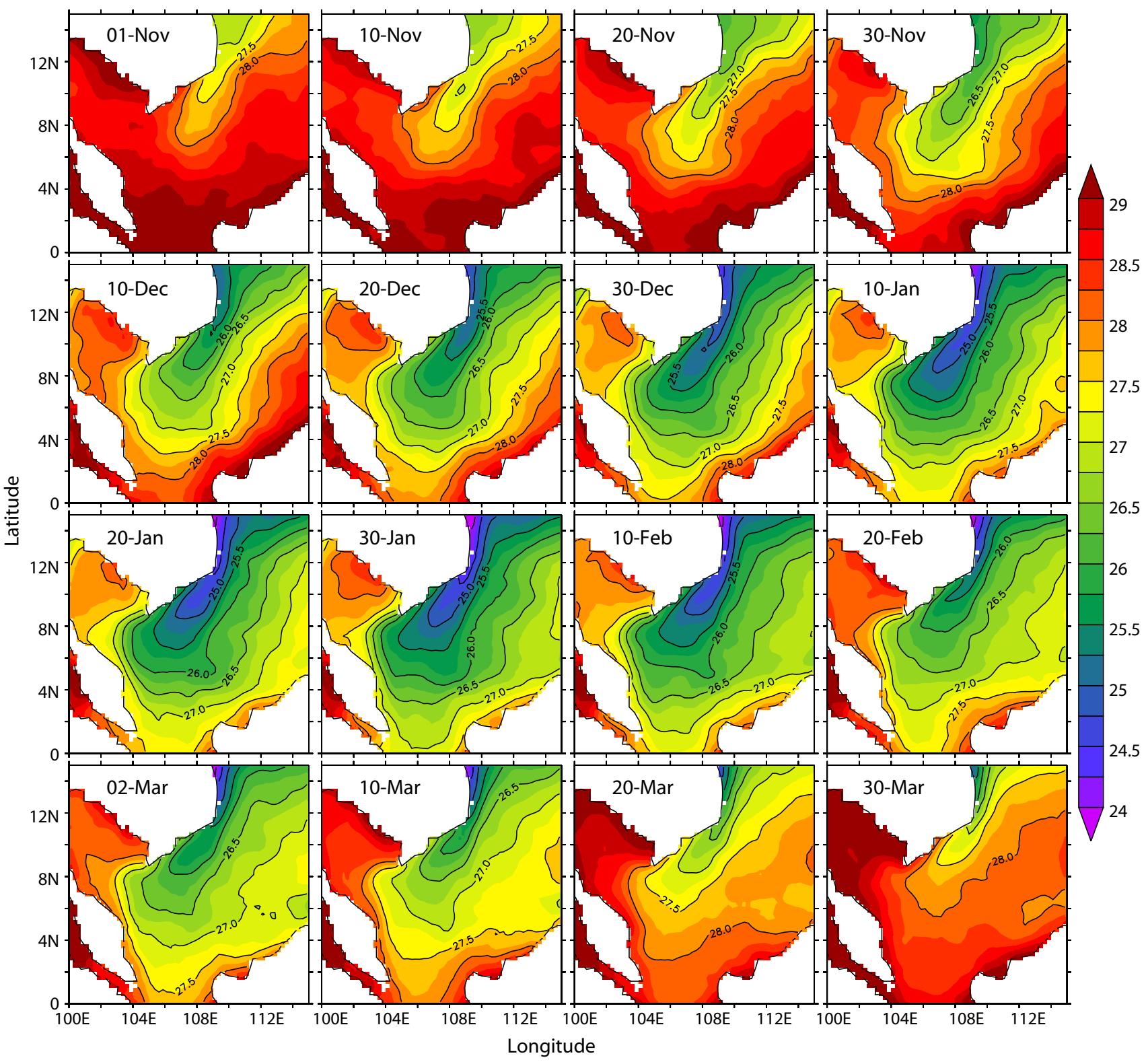

Fig. 2 Evolution of the South China Sea winter cold tongue. The figures are drawn using daily SST climatology computed for the period 19822012

temperature in late January. A narrow band of low SST waters, $<25{ }^{\circ} \mathrm{C}$, is noted along the east coast and south off Vietnam during this period. Finally, with the weakening of northeast monsoon, the CT starts decaying and terminates completely by March.

The standard deviation of SST anomalies over the southern SCS computed from OISSTv2 during the northeast monsoon (November-February) is shown in Fig. 3. The figure shows that the maximum amplitude of peak-topeak SST variability in the southern SCS is located south off Vietnam, where the CT is also prominent. Hence, for further analysis we defined a region in the southern SCS, including the region of high SST variability, bounded between $105^{\circ} \mathrm{E}-110^{\circ} \mathrm{E}$ and $3^{\circ} \mathrm{N}-10^{\circ} \mathrm{N}$. This region is referred here as SCS CT in further analysis. For the sake of understanding the ability of SODA data in reproducing the observed variability over the SCS CT, the SST anomalies computed from OISSTv2 and SODA are compared (Fig. 4). The figure shows that SODA could reproduce the inter-annually varying signals of SST over the CT region well. The correlation and RMS difference between SODA and OISSTv2 are 0.88 and $0.12{ }^{\circ} \mathrm{C}$, respectively.

Considering the validity of equations used for the winddriven transport computation, as a conservative approach, 
Fig. 3 SST standard deviation during the northeast monsoon from OISSTv2 (1982-2012).

The region of maximum SST variability is represented by the box $\left(105^{\circ} \mathrm{E}-110^{\circ} \mathrm{E}\right.$ and $\left.3^{\circ} \mathrm{N}-10^{\circ} \mathrm{N}\right)$

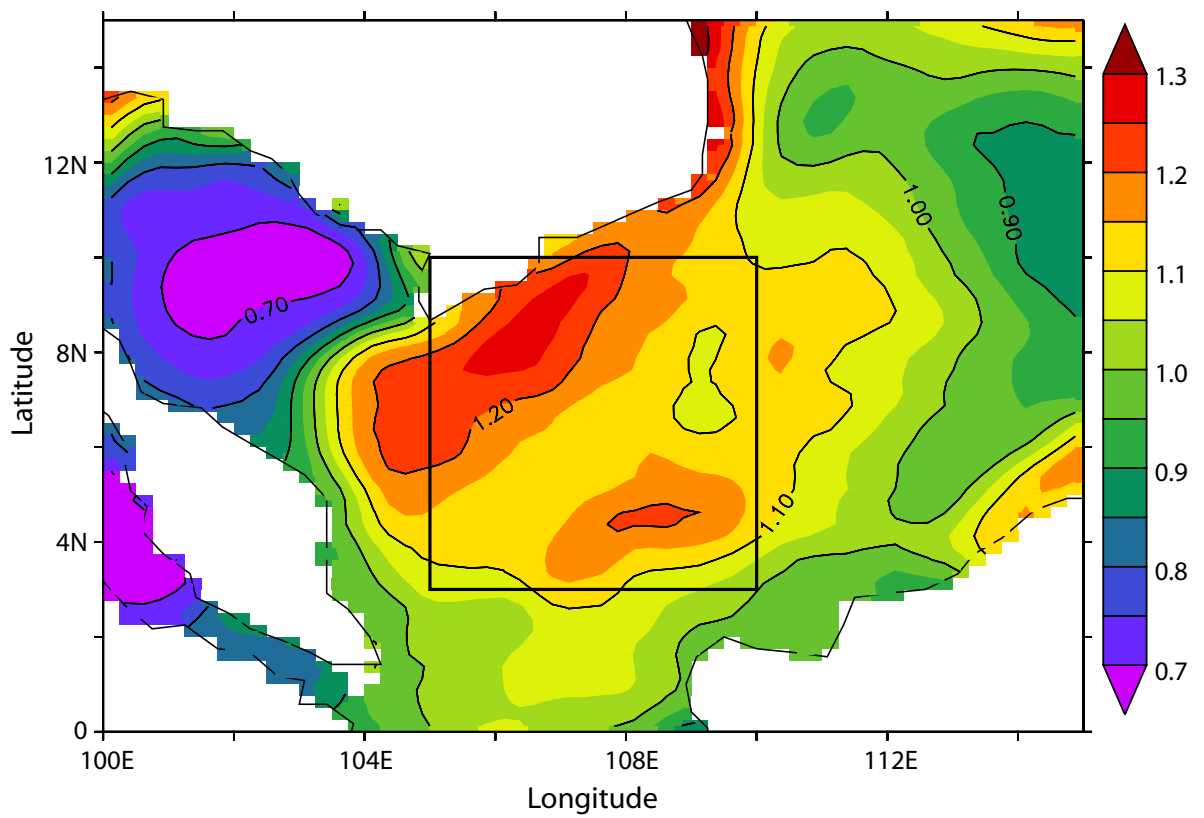

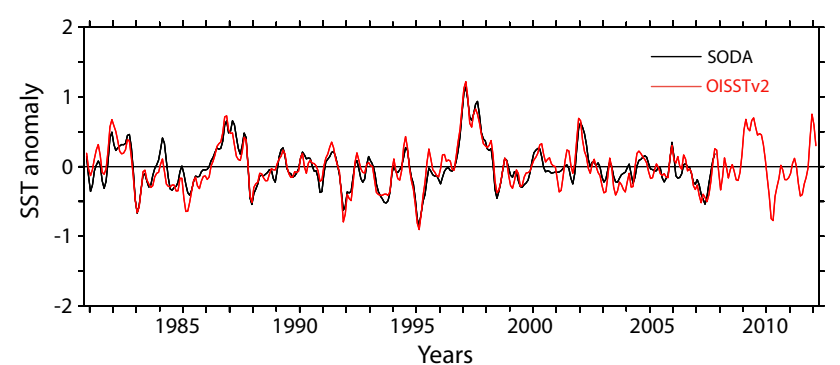

Fig. 4 SST anomaly from OISSTv2 (red line, 1982-2012) and SODA (black line, $1982-2008)$ over the SCS CT $\left(105^{\circ} \mathrm{E}-110^{\circ} \mathrm{E}\right.$ and $\left.3^{\circ} \mathrm{N}-10^{\circ} \mathrm{N}\right)$

the discussions involving the analysis of wind-driven transports are performed north of $5^{\circ} \mathrm{N}$ over the domain $105^{\circ} \mathrm{E}-110^{\circ} \mathrm{E}$ and $5^{\circ} \mathrm{N}-10^{\circ} \mathrm{N}$. Meanwhile discussions on the heat budget analysis are presented for the domain $105^{\circ} \mathrm{E}-110^{\circ} \mathrm{E}$ and $3^{\circ} \mathrm{N}-10^{\circ} \mathrm{N}$, which is defined as the SCS $\mathrm{CT}$ region in our study.

\subsection{Wind-driven ocean transports}

The daily $10 \mathrm{~m}$ wind fields from ERA-interim re-analysis for 1982-2012 period are used for computing the winddriven ocean transport over the Sunda Shelf in the SCS. The climatological evolution of SST and wind-driven transport over the SCS CT is plotted in Fig. 5. The SST climatology averaged over this region is shown in the figure. The northsouth Sverdrup transport (SvT) across $10^{\circ} \mathrm{N}$, Zonal Ekman transport (ZEkT) across $110^{\circ} \mathrm{E}$, meridional Ekman transport $\left(\mathrm{MEkT}_{10 \mathrm{~N}}\right)$ across $10^{\circ} \mathrm{N}$, meridional Ekman transport

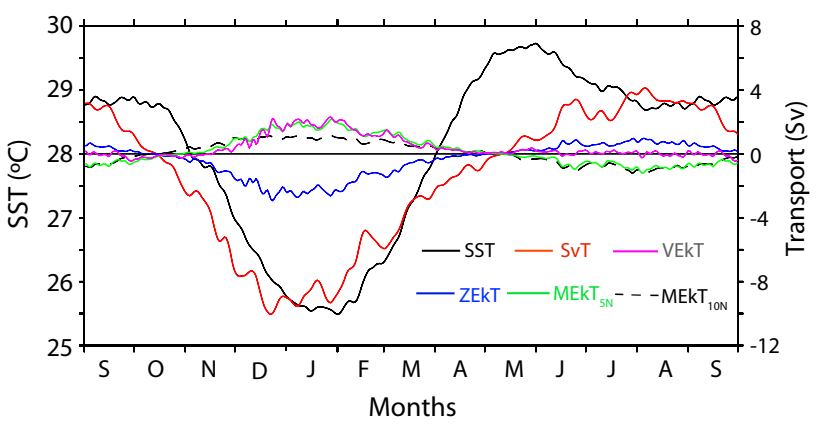

Fig. 5 Climatological evolution of SST $\left({ }^{\circ} \mathrm{C}\right)$ and wind-driven ocean transports $(\mathrm{Sv})$ in the SCS CT region. SST averaged over the region $105^{\circ} \mathrm{E}-110^{\circ} \mathrm{E}$ and $5^{\circ} \mathrm{N}-10^{\circ} \mathrm{N}$ (SST, black line), north-south Sverdrup transport across $10^{\circ} \mathrm{N}$ (SvT, red line), zonal Ekman transport across $110^{\circ} \mathrm{E}$ (ZEkT, blue line), meridional Ekman transport across $10^{\circ} \mathrm{N}$ $\left(\mathrm{MEkT}_{10 \mathrm{~N}}\right.$, dashed line), meridional Ekman transport across $5^{\circ} \mathrm{N}$ $\left(\mathrm{MEkT}_{5 \mathrm{~N}}\right.$, green line $)$ and vertical Ekman transport across bottom of Ekman layer (VEkT, purple line) are shown in the figure

$\left(\mathrm{MEkT}_{5 \mathrm{~N}}\right)$ across $5^{\circ} \mathrm{N}$ and vertical Ekman transport (VEkT) across the bottom of the Ekman layer are also shown in the figure. Selected boundaries represent either the northern $\left(10^{\circ} \mathrm{N}\right)$, eastern $\left(110^{\circ} \mathrm{E}\right)$ or southern $\left(5^{\circ} \mathrm{N}\right)$ boundary of the domain. Here the positive values indicate the eastward/ northward transport or Ekman pumping (downwelling) whereas the negative values represent the westward/southward transport or Ekman suction (upwelling). The average SST over the CT falls below $28^{\circ} \mathrm{C}$ by early November and it continues to drop until the end of January, where the peak surface cooling (SST $<25^{\circ} \mathrm{C}$ ) is observed. Once the winter monsoon starts collapsing in February, the SST over the $\mathrm{CT}$ shows a gradual warming and the transition to warm 
surface temperatures is even rapid during March. Finally, the CT completely disappears from the region by late March/early April (Figs. 2, 5).

The magnitude of wind-driven north-south vertically integrated transport (Sverdrup transport) is much higher than the horizontal (zonal and meridional) and vertical Ekman transports during the winter monsoon in the CT region (Fig. 5). Southward Sverdrup transport across northern boundary starts in mid-October; approximately half a month earlier than the appearance of low SSTs $\left(<28^{\circ} \mathrm{C}\right)$ in the SCS CT. Peak southward Sverdrup transport to the $\mathrm{CT}$ region occurs in mid-December which is about a month prior to the maximum SST cooling. In general, the southward Sverdrup transport leads the SST variations over the CT region by almost half a month during the northeast monsoon period. The zonal and vertical Ekman transports vary almost in the same range $\left( \pm 2 \mathrm{~Sv}, 1 \mathrm{~Sv}=10^{6} \mathrm{~m}^{3} / \mathrm{s}\right)$ during this season. The zonal Ekman transport shows westward transport of about $2 \mathrm{~Sv}$ across eastern boundary of the CT while the meridional Ekman transport is directed towards north. Since the wind-driven transports occur at $90^{\circ}$ clockwise from the wind direction (in northern hemisphere), the northerly and easterly components of the prevailing monsoon winds give rise to the transports in westward and northward direction respectively. Also, the monsoon winds has strong northerly component during this season relative to its easterly component. This results in higher zonal transport as compared to its meridional component. Consistent with the Ekman pumping observed along the coast of Vietnam, vertical transport is directed downward during the northeast monsoon. The convergence along the coast of Vietnam due to the westward zonal Ekman and northward meridional Ekman transports lead to the water pile up and sinking processes. This water sinking process is manifested by the positive Ekman vertical transport during the northeast monsoon.

To accomplish a detailed description on the role of winddriven transports on the evolution of SCS CT, the analysis of spatial distributions of climatological monthly SST (Fig. 6a-d), Sverdrup transport (Fig. 6e-h), zonal Ekman transport (Fig. 6i-1), meridional Ekman transport (Fig. 6mp) and Ekman pumping velocity (Fig. 6q-t) over the Sunda Shelf are performed in this section. In order to have an understanding of the upper ocean circulation, the climatological geostrophic current velocity vectors are overlaid on the SST distribution (Fig. 6a-d). The monthly climatology of geostrophic velocity is computed from weekly geostrophic velocity (from 1993 to 2013) obtained from Ssalto/Ducas multimission altimeter products. Detailed information on the Ssalto/Ducas data products is available in http://www.aviso.oceanobs.com/en/data/productinformation/information-about-mono-and-multi-missionprocessing/ssaltoduacs-multimission-altimeter-products. html. As it flows south, the geostrophic circulation shows strong southward currents along the coast of Vietnam with increased velocity. At around $5^{\circ} \mathrm{N}$, South off Vietnam, the current turns towards left and forms a cyclonic circulation pattern (Fig. 6a-d) that roughly follows the $100 \mathrm{~m}$ bathymetric contour (Fig. 1). Consistent with the evolution of SCS CT seen in the daily climatology (Fig. 2), the peak SST cooling is observed during January (Fig. 6c). The spatial pattern of Sverdrup transport is noted by strong southward flow along the cost of Vietnam and relatively weak northward water transport in the east (Fig. 6e-h).

Figure 6 demonstrates that the evolution of SCS CT is intimately related to the wind-driven ocean transports. Strong southward Sverdrup transport substantially supports the cooling of surface temperature by bringing relatively cold water from the north. However south of Vietnam, the $\mathrm{CT}$ is positioned to the west of southward currents axis. Liu et al. (2004) suggested that the shift in CT location is possibly due to the advection of surface Ekman flow. During the northeast monsoon, the zonal and meridional Ekman transports show westward and northward transports which are higher in December and January, respectively (Fig. 6). The westward zonal Ekman flow causes the CT to shift west of the southward boundary current. Further, the zonal Ekman current brings warm surface waters from the eastern parts of the Sunda Shelf and prevents any eastward spreading of the cold SST region. Thus, the CT appears as a narrow band of low SST region prominent between $105^{\circ} \mathrm{E}$ and $110^{\circ}$ E. Meanwhile, the positive (northward) Ekman meridional transport together with the bathymetry driven cyclonic circulation play a major role in limiting the southward extend of the CT. During winter, the northeasterly winds over the SCS have its maximum along a southwest diagonal axis connecting the Luzon Strait and southern Malay Peninsula (e.g., Liu and Xie 1999). Diagonal orientation of the wind maximum yields strong positive wind stress curl (upwelling) in the left side and negative wind stress curl (downwelling) to the right, along the coast. This downwelling and upwelling motions are represented by the positive and negative Ekman pumping velocities, respectively, in the Fig. 6q-t. The core of downward velocity is observed southeast of Vietnam. In general, the downwelling process tends to increase the ocean mixed layer depth. The wind stress curl induced downwelling further strengthens the upper ocean cooling through the mixing of cold water transported by the boundary current. Along with the withdrawal of northeast monsoon, the horizontal and vertical transports become weak in February and completely disappears by March/April.

Above analysis suggests that the formation, growth and decay of the SCS CT has a very strong relation with the computed wind-driven ocean transports. However, while it provides insights on the dynamical ocean processes 

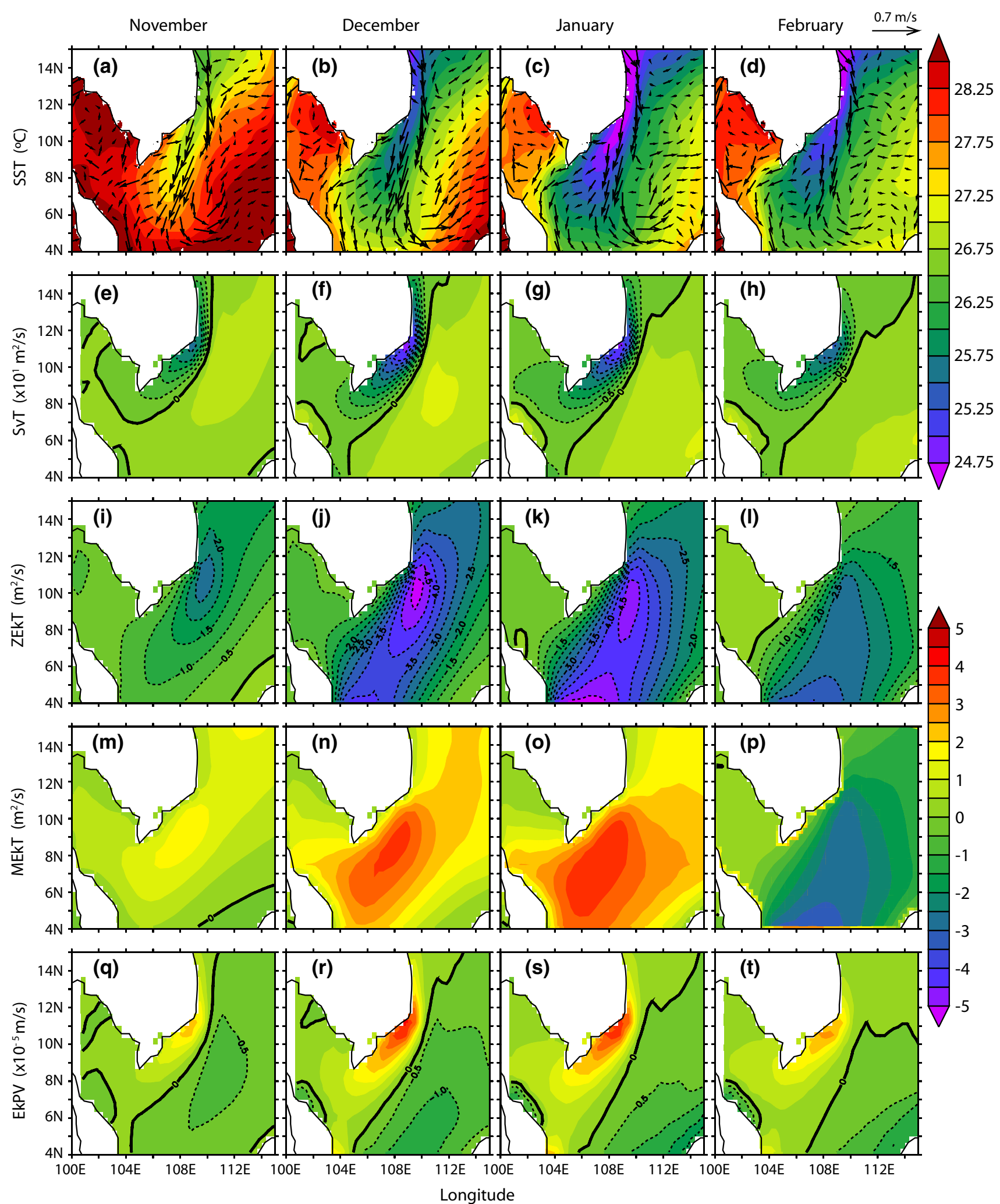

Fig. 6 Climatology of SST (a-d), Sverdrup transport (e-h), zonal Ekman transport (i-l), meridional Ekman transport (m-p) and Ekman pumping velocity $(\mathbf{q}-\mathbf{t})$ in the SCS CT during the northeast monsoon. The SST climatology is overlaid with the geostrophic current climatology. The top color bar represents the SST while the trans-

ports and Ekman pumping velocity are indicated by the bottom color bar. The contours represent negative values. For Sverdrup and horizontal Ekman transports negative values shows southward or westward transports. In case of Ekman pumping negative values indicate upward currents 
responsible for the evolution of the $\mathrm{CT}$, detailed information regarding the underlying thermodynamical processes is missing in this analysis. Also, the analysis shows that the peak of Sverdrup and horizontal Ekman transports occur almost a month prior to the maximum SST cooling over the CT region. This suggests the role of air-sea interaction and ocean thermodynamic processes, such as diffusion, on the evolution of the CT. Hence we have performed the mixed layer heat budget analysis of SCS CT to acquire a comprehensive understanding on the oceanic processes contributing to its formation and decay. The results from the heat budget analysis is discussed in the following section.

\subsection{Mixed layer heat budget of SCS cold tongue}

The oceanic parameters from SODA and sea surface heat flux from NOC flux are used to evaluate the mixed layer heat budget of the SCS CT. The ocean advection and diffusion terms are computed based on the ocean currents, vertical motion and temperature provided by the SODA re-analysis as discussed in the Sect. 3.2. The contribution of surface heat flux is estimated based on the mixed layer depth computed from SODA and air-sea heat fluxes obtained from NOC flux data. SODA data has been used for the upper ocean heat budget analysis of various regions in earlier studies (e.g., Shenoi et al. 2005; Madhusoodanan and Thompson 2011).

The mixed layer heat budget terms averaged over the SCS CT $\left(105^{\circ} \mathrm{E}-110^{\circ} \mathrm{E}\right.$ and $\left.3^{\circ} \mathrm{N}-10^{\circ} \mathrm{N}\right)$ is shown in Fig. 7 . The climatological mixed layer temperature tendency $\left(\partial T_{t}\right)$, net surface heat flux $\left(Q_{f x}\right)$, the sum of vertical advection and vertical diffusion at the base of the mixed layer $\left(Q_{\text {vert-process }}\right)$, horizontal advection $\left(Q_{\text {hadv }}\right)$ and the sum of $Q_{f x}, Q_{\text {vert-process }}$ and $Q_{\text {hadv }}\left(Q_{\text {total }}\right)$ are plotted in the figure. Here, positive values indicate heat gained by mixed layer and negative values denote the loss of heat. MLD averaged over the same region is also shown in the figure.

The mixed layer temperature tendency and MLD shows a clear semi-annual distribution under the influence of northeast and southwest monsoons. The primary and secondary maxima in $\partial T_{t}$ occur in March-April and September respectively while the primary and secondary minima are observed during December and July, respectively. The MLD over the CT has seasonal maxima in January and August/September with the minima seen during May and October/November. Though the heat budget is not exactly closed, the figure suggests that $\partial T_{t}$ and $Q_{\text {total }}$ are varying almost in same phase and the two curves closely match. The usage of datasets from different sources may be one possible reason for this discrepancy. The uncertainties in the surface flux observation, assimilation of temperature observations in SODA and computational errors can be other sources of imbalance in the heat budget. However,

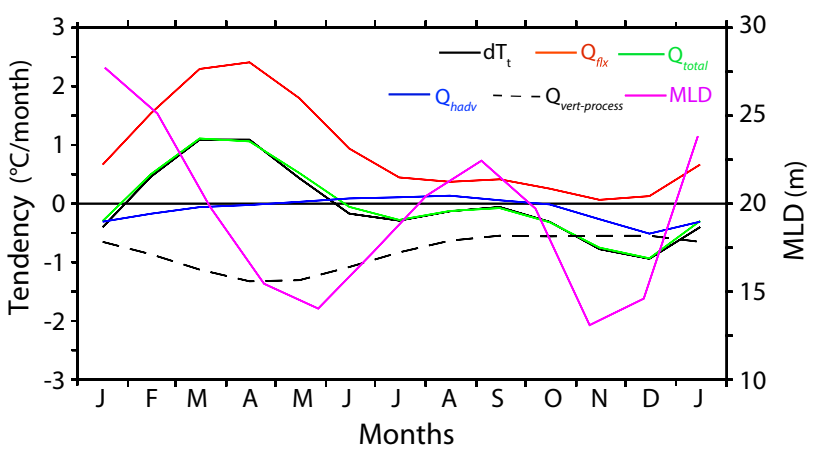

Fig. 7 Mixed layer heat budget climatology of the SCS CT $\left(105^{\circ} \mathrm{E}-110^{\circ} \mathrm{E}\right.$ and $\left.3^{\circ} \mathrm{N}-10^{\circ} \mathrm{N}\right)$. Mixed layer temperature tendency $\left(\partial T_{t}\right.$, black line $)$, net surface heat flux $\left(Q_{f t x}\right.$, red line $)$, vertical ocean processes $\left(Q_{\text {vert-process }}\right.$, black dash $)$, horizontal advection $\left(Q_{\text {hadv }}\right.$, blue line $)$ and the sum of $Q_{f t x}, Q_{\text {vert-process }}$ and $Q_{\text {hadv }}\left(Q_{\text {total }}\right.$, green line $)$ are shown in the figure. The purple line indicates the MLD (m) averaged over the SCS CT (right $y$-axis)

it is encouraging to see that the positive/negative peaks in $\partial T_{t}$ and $Q_{\text {total }}$ are coherent and the error is relatively smaller than the standard deviation of $\partial T_{t}$. This give us the confidence to perform further analysis for understanding the seasonal changes of various terms in the heat budget. The roles of oceanic processes and atmospheric forcing in driving the mixed layer temperature variations are discussed here.

\subsubsection{Ocean dynamics}

In seasonal cycle $\partial T_{t}$ tends to become negative with the onset of southwest monsoon, accompanied by a rapid reduction in the magnitude of net heat flux and ocean vertical process (Fig. 7). Though there is an increase in the mixed layer temperature during September, the temperature tendency remains negative from June to January. Thereafter the mixed layer warming occurs mainly due to an increase in the net surface heat flux. The analysis shows that surface heat flux is the dominant factor that determines the SST seasonal cycle. The heat budget demonstrates an offsetting of net surface heat flux and vertical processes from spring to fall seasons while a balance between the horizontal advection, vertical ocean processes and net surface heat flux is observed during the northeast monsoon. The flux contribution due to the vertical ocean processes reaches its minimum magnitude during the southwest monsoon, when the surface heat flux also decreases.

The mixed layer heat budget is noted by the dominance of vertical ocean processes over the horizontal advection except during the winter season. Though weaker in magnitude, the horizontal heat advection tends to be positive during the southwest monsoon period. Meanwhile, the horizontal advection has significant contribution to the 
total mixed layer temperature variation during the northeast monsoon. The vertical ocean processes tend to cool the mixed layer temperature throughout the year. Temperature loss due to the vertical processes attains its maximum in April-May approximately coinciding with the first MLD minima. From February to May, weakening of the northeast monsoon results in rapid shoaling of the MLD and reduction in heat loss due to the horizontal advection. The cooling effect due to the vertical processes gradually increases during this period and together with the reduction of surface heat flux leads to decreasing temperature tendency by April. With the onset of the northeast monsoon, the horizontal advection gradually increases and contributes significantly to the temperature cooling. Strong northeast monsoon currents bring cold water from the northern SCS during this period. To the CT region, the cold-water advection occurs largely through the northern boundary. Impact of horizontal fluxes on the evolution of the CT is almost same as the vertical processes.

To understand the contributions of individual heat budget components to the SST changes, we performed a linear regression analysis. Linear regressions of the surface heat flux, horizontal advection and the vertical processes on the mixed layer temperature tendency are computed. The linear regressions of $\partial T_{t}, Q_{f i x}, Q_{v e r t-p r o c e s s}, Q_{h a d v}$ and $Q_{t o t a l}$ averaged over the SCS CT region are plotted in Fig. 8. Monthly anomalies of the individual components after removing their respective annual mean are shown. The regression coefficients for net surface heat flux, vertical ocean processes and horizontal advection are 1.58, -0.65 and 0.14 respectively. The seasonal cycle of $Q_{f x}, Q_{h a d v}$ and $Q_{\text {vert-process }}$ appears to be synchronized with the changes in $\partial T_{t}$, where $Q_{f i x}$ and $Q_{h a d v}$ varies in phase with $\partial T_{t}$. Meanwhile, the changes in vertical ocean processes are exactly in the opposite phase of $\partial T_{t}$. Further analysis revealed that $Q_{\text {vert-process }}$ is dominated by the vertical diffusion flux and the vertical advection is relatively weak (figure not shown). It is obvious that a warmer mixed layer eventually loses more heat to the relatively cooler subsurface layers through the diffusive processes and vice versa. Moreover, a regression analysis has been conducted to understand the individual contributions of vertical advection, vertical diffusion, zonal advection and meridional advection fluxes. The analysis revealed that the vertical and the zonal advections have negligible effect in determining SST over this region.

Figure 8 shows that $\partial T_{t}, Q_{f t x}$ and $Q_{h a d v}$ tend to be lower than their annual mean during the period from June to January. From October onwards, prior to the onset of northeast monsoon, the surface heat flux shows significant negative anomalies and becomes minimal in December. The positive anomaly in $Q_{\text {vert-process }}$ during the southwest and northeast monsoons reflects the reduced heat loss due to the mixed layer cooling. Moreover the heat loss through vertical

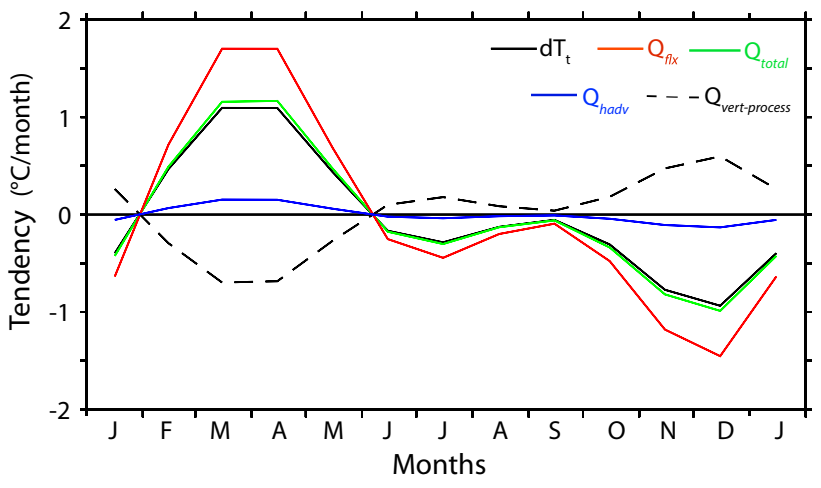

Fig. 8 Climatological mixed layer heat budget of the SCS CT expressed as linear regression w.r.t. mixed layer temperature tendency. Mixed layer temperature tendency $\left(\partial T_{t}\right.$, black line $)$, net heat flux $\left(Q_{f l x}\right.$, red line $)$, vertical ocean processes $\left(Q_{\text {vert-process }}\right.$, black dash), horizontal advection $\left(Q_{\text {hadv }}\right.$, blue line $)$ and sum of $Q_{f x}, Q_{\text {vert-process }}$ and $Q_{\text {hadv }}\left(Q_{\text {total }}\right.$, green line $)$ averaged over the SCS $\mathrm{CT}$ are shown. Corresponding annual mean values are removed from the individual terms

processes, mainly through the diffusive processes, is at a minimum when peak cooling is observed in the $\mathrm{CT}$ region.

Liu et al. (2004) estimated the total SST cooling in the $\mathrm{CT}$ as $\sim 1.5{ }^{\circ} \mathrm{C}$ from November to December. In our study, spatial average of the mixed layer averaged temperature over the CT shows peak cooling of about $1{ }^{\circ} \mathrm{C} /$ month in December (Fig. 7). The contribution of net surface heat flux to the mixed layer heat budget almost becomes zero during this period. Meanwhile, the horizontal advection and vertical ocean processes contribute equally to the mixed layer cooling ( -0.5 ${ }^{\circ} \mathrm{C} /$ month, Fig. 7). However, it should be noted that the seasonal variability of $Q_{h a d v}$ and $Q_{\text {vert-process }}$ are relatively much weaker than the $Q_{f x}$. In the seasonal cycle, the $Q_{f i x}$ plays a significant role in the mixed layer temperature cooling during the southwest and northeast monsoon periods (Fig. 8). Indeed, the relative influence of surface heat flux on the CT evolution in December is much higher $\left(\sim-1.5{ }^{\circ} \mathrm{C} /\right.$ month) than the contributions from horizontal advection $\left(\sim-0.25{ }^{\circ} \mathrm{C} /\right.$ month $)$ and vertical ocean processes $\left(\sim+0.5{ }^{\circ} \mathrm{C} /\right.$ month $)$. The regression analysis clearly reveals the dominance of the surface heat flux in the mixed layer heat budget. Negative temperature tendency from June to January is dominantly forced by the negative surface heat flux anomalies. The significance of surface heat flux in the onset, growth and decay of the cold tongue is clearly evident in the figure.

The spatial distribution of heat budget climatology over the Sunda Shelf expressed as linear regression w.r.t. mixed layer temperature tendency is shown in Fig. 9. The monthly anomalies computed by removing their annual mean are given. As observed in the SST evolution (Fig. 3), negative trend in $\partial T_{t}$ originates along the east coast of Vietnam in 


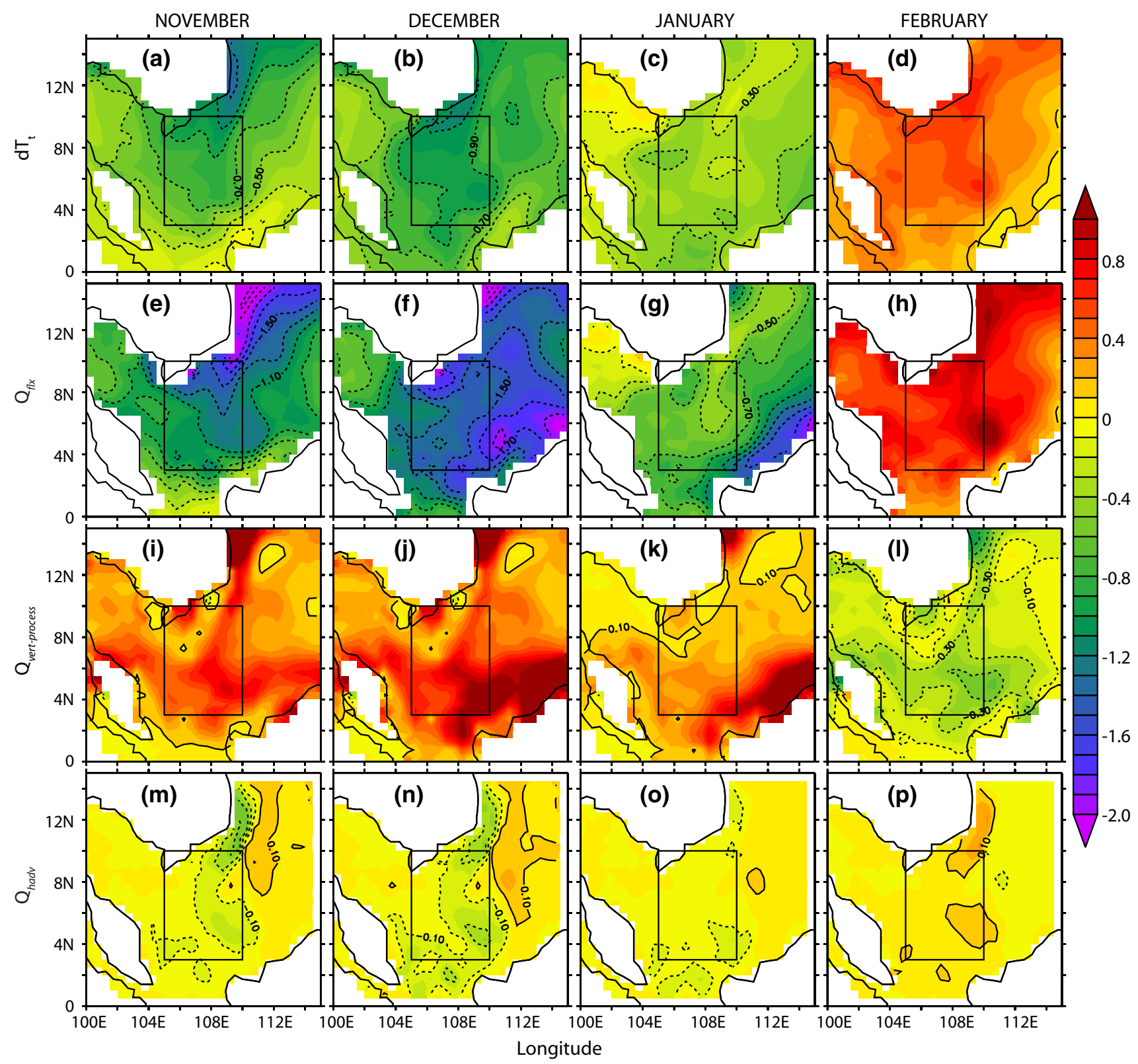

Fig. 9 Spatial distribution of mixed layer heat budget climatology $\left({ }^{\circ} \mathrm{C} /\right.$ month) during the northeast monsoon period expressed as linear regression w.r.t. the mixed layer temperature tendency. The mixed

November and persists up to January (Fig. 9a-c). Thereafter, the mixed layer warming process begins and $\partial T_{t}$ turns positive by February (Fig. 9d) coinciding with the withdrawal of northeast monsoon. Visual inspection of the figure denotes a good correlation between $\partial T_{t}$ and $Q_{f x}$ in the Sunda Shelf. Coherent variations in the spatial distribution of $\partial T_{t}$ and $Q_{f i x}$ are consistent with the results that are presented above. Significant negative heat flux anomalies are seen along east/southeast coasts of Vietnam in November (Fig. 9e). Subsequently, the heat flux anomalies show a progressive increase in space and magnitude until February layer temperature tendency $(\mathbf{a}-\mathbf{d})$, net heat flux $(\mathbf{e}-\mathbf{h})$, vertical ocean processes $(\mathbf{i}-\mathbf{l})$ and horizontal advection $(\mathbf{m}-\mathbf{p})$ are shown. Corresponding annual mean values are removed from the individual terms

(Fig. 9f-h). The cooling of ocean eventually results in a reduction in heat loss through vertical diffusion at the base of the mixed layer which is indicated by the positive anomalies in the vertical ocean processes (Fig. 9i-k). The warming of mixed layer or SST by February with diminishing monsoon leads to an increase in the diffusive heat loss and negative anomalies in $Q_{\text {vert-process }}$ (Fig. 91). Though the contribution of horizontal advection is relatively small, the advection of cold water along the coast of Vietnam is clearly evident in the heat budget analysis (Fig. 9m, n). The horizontal advective processes are prominent off the 


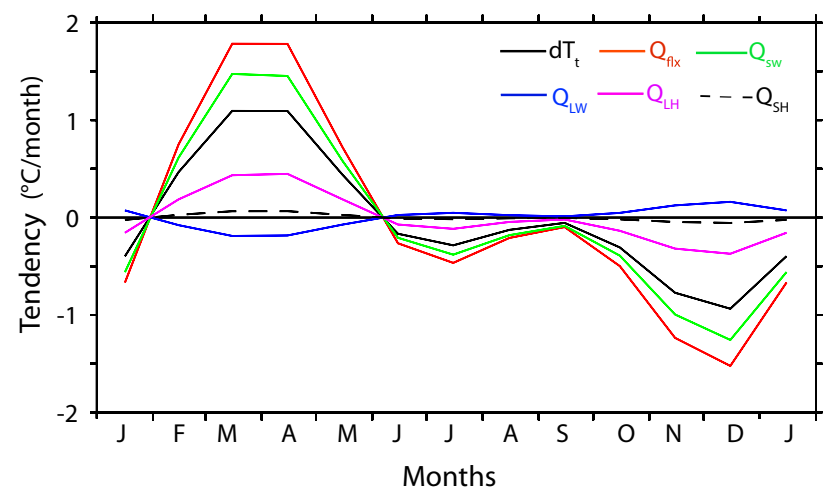

Fig. 10 Linear regression of the climatological net surface heat flux and its components w.r.t. the mixed layer temperature tendency averaged over the SCS CT. Mixed layer temperature tendency $\left(\partial T_{t}\right.$, black line $)$, net heat flux $\left(Q_{f t x}\right.$, red line), shortwave flux $\left(Q_{S W}\right.$, green line $)$, longwave flux ( $Q_{L W}$, blue line), latent heat flux $\left(Q_{L H}\right.$, purple line $)$ and sensible heat flux $\left(Q_{S H}\right.$, dashed line $)$ are plotted. Corresponding annual mean values are removed from the terms

southeastern and eastern coasts of Vietnam in November and December.

\subsubsection{Atmospheric forcing}

The heat budget analysis suggests that the dominant process that drives SST cooling over the SCS CT is the atmospheric forcing. The individual contributions of the short wave flux absorbed within the mixed layer $\left(Q_{S W}\right)$, net long wave flux $\left(Q_{L W}\right)$, latent heat flux $\left(Q_{L H}\right)$ and sensible heat flux $\left(Q_{S H}\right)$ to the net surface heat flux is shown in Fig. 10. The mixed layer temperature tendency $\left(\partial T_{t}\right)$ and net surface heat flux $\left(Q_{f x}\right)$ are also shown. Linear regressions of the air-sea flux terms w.r.t. the mixed layer temperature tendency are given. The linear regression coefficients for $Q_{f i x}, Q_{S W}, Q_{L W}$, $Q_{L H}$, and $Q_{S H}$ are $1.58,1.26,-0.15,0.42$ and 0.05 respectively. The seasonal shape of $Q_{f x}$ is mainly determined by the changes in $Q_{S W}, Q_{L W}$ and $Q_{L H}$ fluxes. The role of sensible heat flux is relatively small in the heat budget. The seasonal variations in the $Q_{S W}$ is essentially driven by the seasonal March of the sun and the monsoons. During the northeast monsoon, the increased cloudiness and highest solar zenith angle results in the lowest short wave flux. Similarly, the cloudiness associated with the southwest monsoon produces the secondary minimum in the $Q_{S W}$. Seasonal cycle of $Q_{L H}$ is mainly dependent on the surface wind speed variations. It is obvious that the $Q_{L H}$ anomaly is higher during the monsoon periods when the winds are stronger over the region. Conversely, calm winds results in relatively low latent flux release from the ocean during the pre-monsoon (April-May) and inter-monsoon (October) periods. The increased shortwave flux and reduced latent heat flux induces positive primary and secondary maxima in the seasonal cycle of $Q_{f t x}$ during the pre-monsoon and inter-monsoon periods. Meanwhile, the monsoonal processes such as the reduced short wave flux due to increased cloudiness and greater latent heat flux release due to strong winds are responsible for the negative $Q_{f t x}$ anomalies.

The net surface heat flux shows significant reduction during the development phase of the SCS CT, which is mainly attributed to the decrease in short wave flux and increase in latent heat flux. The negative anomalies in shortwave flux is essentially due to the increased cloudiness and highest solar zenith angle during the boreal winter, while the increase of latent heat flux is forced by the strong northeast monsoon winds. The regression analysis suggests that the relative contribution of short wave flux is higher than the latent heat flux by a factor of three.

The spatial distribution of linear regression of the net surface heat flux and its components w.r.t. $\partial T_{t}$ over the Sunda Shelf is shown in Fig. 11. For surface heat fluxes the individual contribution from $Q_{S W}, Q_{L W}$ and $Q_{L H}$ are included in the analysis. The $Q_{S H}$ term is omitted from further analysis since its contribution is relatively small. Annual mean values are subtracted from the terms to understand their seasonal variations. As discussed earlier, the net surface heat flux decrease associated with the mixed layer cooling in the SCS CT region during the northeast monsoon is dominantly driven by short wave radiation (Fig. 11i-k) with the latent heat flux playing a secondary role (Fig. $11 \mathrm{~m}-\mathrm{o}$ ). A good correlation is seen between the net heat flux and short wave radiation anomalies over this region. Meanwhile in the south of Vietnam, the latent heat flux anomalies are found to have a significant role in driving the net heat flux variation (Fig. $11 \mathrm{~m}-\mathrm{o}$ ).

The net heat flux almost follows the short wave radiation in the SCS CT except for a small region south of Vietnam where the latent heat flux anomalies are dominant. The $Q_{f t x}$ and $Q_{S W}$ shows cooling of about -1 to $-2{ }^{\circ} \mathrm{C} /$ month in November-January and thereafter both these fluxes show a gradual warming tendency of $0.8-1{ }^{\circ} \mathrm{C} /$ month in February. Meanwhile, the latent heat flux anomaly noted by a remarkable increase of -0.8 to $-1.6{ }^{\circ} \mathrm{C} /$ month from November to December in the region south of Vietnam (Fig. $11 \mathrm{~m}, \mathrm{n}$ ). Subsequently, its contribution to the net heat flux decreases to $-0.4{ }^{\circ} \mathrm{C} /$ month in January (Fig. 11o). When the northeast monsoon winds become weak, the latent heat flux also decreases over the region thereby aiding the warming of mixed layer though reduced heat loss (Fig. 11p). Temporal variations in the long wave radiation is fairly small and it remains positive during the development and peak phases of the cold tongue (Fig. 11q-s). The cool SSTs result in reduced heat loss through long wave fluxes. Whereas associated with the warming of mixed layer in February, the longwave flux also increases and eventually lead to negative flux anomalies (Fig. 11t). 

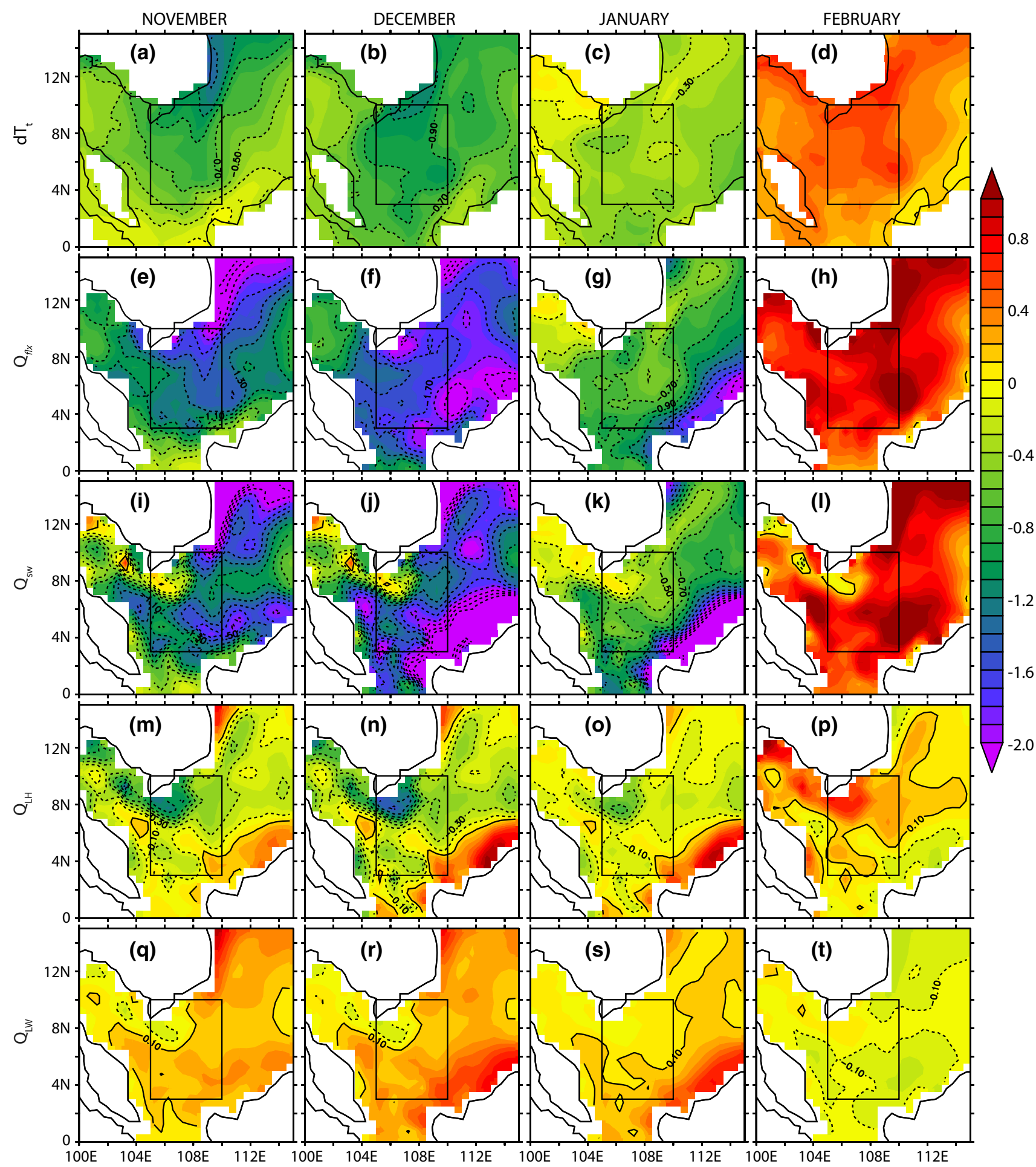

Fig. 11 Spatial distribution of the climatological net surface heat flux and its components $\left({ }^{\circ} \mathrm{C} /\right.$ month $)$ expressed as linear regression w.r.t. the mixed layer temperature tendency, for the northeast monsoon. The mixed layer temperature tendency $(\mathbf{a}-\mathbf{d})$, net heat flux $(\mathbf{e}-\mathbf{h})$,

shortwave flux (i-l), latent heat flux (m-p) and longwave flux $(\mathbf{q}-\mathbf{t})$ are shown. Corresponding annual mean values are removed from the individual terms 
Fig. 12 a Anomalies of OISSTv2 SST averaged over $105^{\circ} \mathrm{E}-110^{\circ} \mathrm{E}$ and $5^{\circ} \mathrm{N}-10^{\circ} \mathrm{N}$ (black line), Sverdrup transport across $10^{\circ} \mathrm{N}$ (red line), zonal Ekman transport across $110^{\circ} \mathrm{E}$ (blue line), meridional Ekman transport across $5^{\circ} \mathrm{N}$ (black dash) and vertical Ekman transport across the bottom of Ekman layer (purple line) for the northeast monsoon. $\mathbf{b}$ Anomalies of mixed layer heat budget terms $\left({ }^{\circ} \mathrm{C} /\right.$ month $)$ averaged over the SCS CT region expressed as linear regressions w.r.t. the mixed layer temperature tendency. Anomalies of mixed layer temperature tendency $\left(\partial T_{t}\right.$, black line $)$, net heat flux $\left(Q_{f t x}\right.$, red line $)$, vertical ocean processes $\left(Q_{\text {vert-process }}\right.$, blue dash) and horizontal advection $\left(Q_{\text {hadv }}\right.$, green line $)$ are shown. c SODA SST anomalies (black line) during the northeast monsoon averaged over the SCS CT overlaid with the December nino3 index (red line). Normalized time series are plotted. The correlation between SSTA and nino 3 index is 0.65
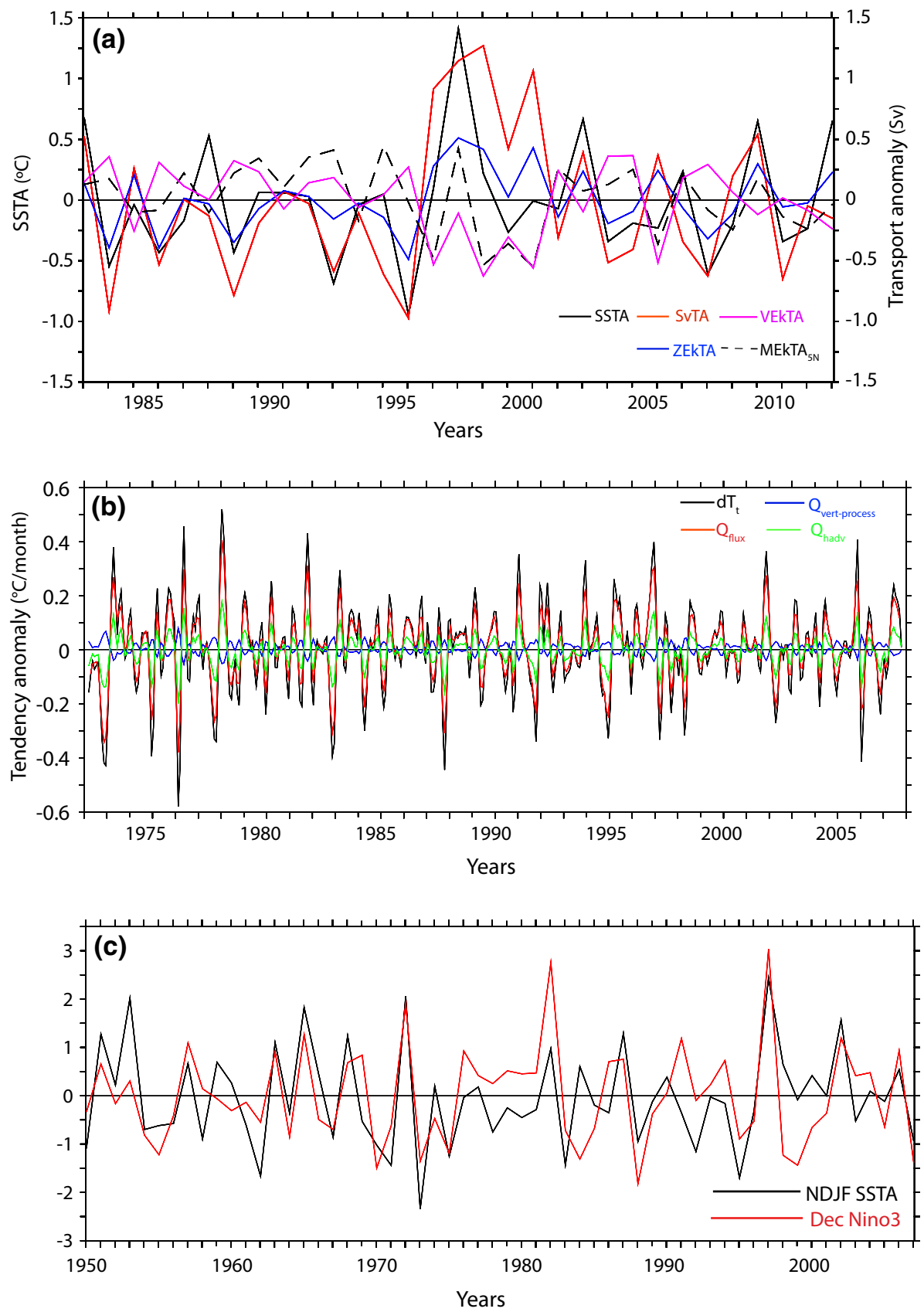

\subsection{Inter-annual variability of the SCS CT}

The SST over the SCS exhibit significant inter-annual variability in response to various regional and global phenomena (Wang et al. 2006; Fang et al. 2006; Thompson and Tkalich 2014). Over the Sunda Shelf, in the southern SCS, observed SST variability is mainly associated with the changes in SCS cold tongue (Fig. 2). The ENSO and monsoons are observed as major forcing factors for the SCS CT variability (Liu et al. 2004, 2005). Inter-annual variability of the SST over the CT region and the processes responsible for it are investigated in this section. To begin with, the analysis of anomalous wind-driven ocean transports associated with the CT variability is presented. Anomalies of OISSTv2 SST (SSTA) averaged over $105^{\circ} \mathrm{E}-110^{\circ} \mathrm{E}$ and $5^{\circ} \mathrm{N}-10^{\circ} \mathrm{N}$, Sverdrup transport (SvTA) across $10^{\circ} \mathrm{N}$, zonal Ekman transport (ZEkTA) across $110^{\circ} \mathrm{E}$, meridional Ekman transport (MEkTA) across $5^{\circ} \mathrm{N}$ and vertical Ekman transport (VEkTA) across the bottom of Ekman layer during the northeast monsoon are shown in Fig. 12a. Correlations between the SSTA and SvTA, ZEkTA, MEkTA, and VEkTA are $0.65,0.75,0.13$ and -0.36 respectively. The inter-annual variability of SCS CT is significantly correlated to the wind-driven ocean transports except to 
MEkTA. Strong positive (negative) anomalies in SST are closely associated with the weakening (strengthening) of the southward Sverdrup and westward zonal Ekman transport anomalies. Liu et al. (2004) suggested that the anomalous warming of the CT is linked with the weakening of northeast monsoon. The diminished monsoon winds lead to a reduction in southward advection of cold water by the boundary currents along the Vietnam coast. Conversely, a strong CT coincides with an enhanced northeast monsoon (Koseki et al. 2013). The robust monsoon winds triggers strong slope current and thereby increased advection of cold water to the region which is illustrated by negative Sverdrup transport anomalies. The wind stress curl during the northeast monsoon induces downwelling currents along the coast of Vietnam. When the monsoon winds become strong, the downwelling also strengthens. This is demonstrated by the significant negative correlation between SSTA and VEkTA.

The thermodynamical processes associated with the inter-annual mixed layer temperature anomalies in the SCS $\mathrm{CT}$ are also investigated through the heat budget analysis. Monthly mean anomalies of heat budget terms averaged over the SCS CT region $\left(105^{\circ} \mathrm{E}-110^{\circ} \mathrm{E}\right.$ and $\left.3^{\circ} \mathrm{N}-10^{\circ} \mathrm{N}\right)$ expressed as linear regression w.r.t. $\partial T_{t}$ is shown in Fig. 12b. Corresponding regression coefficients of $Q_{f x}$, $Q_{\text {hadv }}$ and $Q_{\text {vert-process }}$ are $0.88,0.33$ and -0.12 , respectively. Though there is a small discrepancy, these three terms explain most of the mixed layer temperature changes in the cold tongue. The surface net heat flux remains the dominant process in driving the mixed layer temperature variability in the cold tongue on inter-annual time scale as well. The positive and negative peaks in $\partial T_{t}$ coincides with strong anomalies in the surface heat flux. The variation of vertical ocean process in the opposite phase of $\partial T_{t}$ indicates that it acts against the temperature change. Meanwhile, the horizontal advection anomalies aids the temperature warming or cooling. It is interesting to note that on interannual time scale, the horizontal advection has a relatively important role in the mixed layer heat budget than the vertical processes, almost by a factor of about three, which is substantially different from the seasonal climatology. This result is consistent with our earlier analysis of wind-driven transport anomalies, where the Sverdrup and zonal Ekman transport anomalies are highly correlated with the SST anomalies over the SCS CT.

Liu et al. (2004) showed that during the period from 1982 to 2003, the winter SST anomalies averaged over the region $106^{\circ} \mathrm{E}-111^{\circ} \mathrm{E}$ and $5^{\circ} \mathrm{N}-10^{\circ} \mathrm{N}$ shows significant correlation $(r=0.727)$ with the ENSO index. In a related study, Thompson and Tkalich (2014) used a regional ocean model simulation to understand the mixed layer temperature variability in the southern SCS. Their study revealed that the first dominant model of mixed layer temperature variability in the southern SCS is characterized by a basinwide warming/cooling and it is significantly correlated to the ENSO phenomenon. To further address the influence of ENSO on SST variability over the SCS CT, we used a relatively long time series of data spanning over a period from 1950 to 2008. SODA SST anomaly averaged over the CT region during the northeast monsoon is plotted against the December Nino3 index in Fig. 12c. The Nino3 index represents the intensity of ENSO events and it is defined as the average of SST anomalies over the region $5^{\circ} \mathrm{N}-5^{\circ} \mathrm{S}$ and $170^{\circ} \mathrm{W}-120^{\circ} \mathrm{W}$ in the Pacific Ocean. The figure shows that the cold tongue SST anomalies are significantly linked to the Nino3 index. The correlation between these two are 0.65 which is above $99 \%$ significance level. Positive/negative excursions in the SST anomalies mostly coincides with variations in the Nino3 index. This result is consistent with an earlier study by Liu et al. (2004). Air-sea heat fluxes in the SCS are influenced by the ENSO events through atmospheric tele-connections. The influence of ENSO on remote ocean basins is explained through the "Atmospheric Bridge" mechanism (Klein et al. 1999; Alexander et al. 2002). In general, there is a tendency that negative northeast monsoons occur in the El Nino years and vice versa during the La Nina events (Tomita and Yasunari 1996; Jhun and Lee 2004). As El Nino develops in the Pacific Ocean, the East-Asian northeast monsoon becomes weak, resulting in a reduced circulation in the SCS (Chao et al. 1996). Thus, the clear skies and weakened monsoon lead to an increase in shortwave radiation and decrease in latent heat flux release from the ocean. Eventually, this results in warming of the ocean through net surface heat flux gain. Also, the transport of cold water along the coast of Vietnam will be weakened due to the reduced monsoon circulation and it will lead to the appearance of warmer SSTs in the CT region.

Most of the mixed layer warming events in the cold tongue is associated with the El Nino in the Pacific Ocean (Fig. 12b). For instance, mixed layer warming during the years 1982-1983, 1991-1992, 1994-1995, 1997-1998, 2002-2003 and 2006-2007 co-occurred with either strong or moderate El Nino events. Up to a certain extent this relation holds well during the La Nina events as well (e.g., the mixed layer cooling during 1973-1974, 1975-1976, 19881989, 1995-1996 and 1998-1999). Meanwhile, the strong/ weak northeast monsoons which occurred without La Nino/ El Nino are responsible for a few mixed layer cooling (e.g., 1976-1977, 1983-1984 and 1984-1985)/warming (e.g., 1978-1979) events.

\section{Summary}

The weather and climate over the SCS and adjacent regions are highly influenced by the Southeast Asian 
monsoons and due to its geographical location in the middle of Indo-Pacific warm pool. During the northeast monsoon, a noticeable gap in the Indo-Pacific warm pool appears over the Sunda Shelf in the SCS, and the SST over this region is considerably lower than the eastern Indian and western Pacific Oceans. The band of low SST $\left(<28{ }^{\circ} \mathrm{C}\right)$ extending along the southeastern coast and south of Vietnam is known as the SCS CT. With the arrival of northeast monsoon in November, there is a gradual fall in the SST and it attains maximum cooling by January. Spatial average of SST climatology over the $\mathrm{CT}$ reaches as low as $25.5^{\circ} \mathrm{C}$ in late January. Along with the withdrawal of winter monsoon, this SST cold anomaly also disappears from the region, however its transition to the warm regime is rather vigorous. Climatological evolution of the SCS CT and the oceanic processes responsible for SST/mixed layer temperature changes have been investigated in the present study using a set of observational as well as ocean-atmosphere re-analysis datasets.

The seasonally varying monsoons have a strong influence in shaping the basin scale circulation and temperature distributions in the SCS (Wyrtki 1961; Qu et al. 2005). The wind-driven ocean transports are closely associated with the SST evolution over the CT. The north-south Sverdrup transport demonstrates strong southward transport during the northeast monsoon period while it leads the SST cooling by almost half a month. The southward Sverdrup transport aids the SST cooling by bringing relatively cold water from the northern regions. The zonal and meridional Ekman transports exhibit relatively weak westward and northward transports to the CT region during this period. The horizontal Ekman transports and bathymetry of the region appear to play a significant role in regulating the shape and spatial extent of the CT. The wind stress curl induced downwelling in the southeast of Vietnam enhances the upper ocean cooling through the vertical mixing of cold water transported by the western boundary current.

The mixed layer heat budget analysis of the SCS CT region has been performed to understand the role of oceanic processes and atmospheric forcing in driving the SST variability. In the seasonal cycle, the mixed layer temperature tendency denotes significant cooling with the onset of southwest and northeast monsoons. The surface heat flux is the dominant factor that controls the seasonal SST changes. Surface heat flux and vertical ocean processes reach their minimum magnitudes during the monsoon periods. The horizontal heat advection tends to warm the mixed layer during the southwest monsoon though it is weaker. In general, the mixed layer heat budget of SCS CT is noted by the dominance of vertical ocean processes over the horizontal advection except in the northeast monsoon.
During the development of SCS CT, the surface heat flux shows significant negative anomaly along with relatively weak contribution from horizontal advection. Further, the linear regression analysis clearly revealed the dominance of the surface heat flux in the SST cooling process. With the onset of the northeast monsoon, the horizontal advection gradually increases and aids the temperature cooling. Strong northeast monsoon currents bring cold water from the northern SCS. The horizontal advective processes are prominent off the southeastern and eastern regions of Vietnam. Meanwhile, the vertical ocean processes play only a passive role in the CT evolution since it is dominated by the diffusive processes. The heat budget analysis suggests that the mixed layer cooling due to the reduction in surface heat flux and increase in horizontal advection flux are dominant mechanisms responsible for development of the SCS CT.

The seasonal variations of net surface heat flux over the cold tongue region are mainly driven by the short wave and latent heat fluxes. The decrease in net surface heat flux associated with the SST cooling over the CT region is mainly controlled by the reduced short wave flux and increased latent heat flux. The increased cloudiness and highest solar zenith angle are attributed to the negative anomalies in shortwave radiation, whereas strong northeast monsoon winds are responsible for the enhanced latent heat flux release from the ocean. In general, the relative contribution of short wave flux is almost three fold higher than the latent heat flux in the SST cooling. The latent heat flux anomalies are particularly important in determining the net surface heat flux changes in the region south of Vietnam. Previous studies on the SCS CT have considered the southward advection of cold water as the dominant process contributing to its formation (e.g., Liu et al. 2004; Varikoden et al. 2010). Meanwhile, the present study suggests that net surface heat flux decrease during the northeast monsoon is the primary cooling mechanism responsible for the development of the SCS CT. The horizontal advection of cold water by the western boundary current along the coast of Vietnam is relatively weak and plays only a secondary role. Also, the study suggests that wind-driven ocean transports have a significant role in regulating the shape and spatial extent of the CT. The important ocean-atmospheric processes responsible for the development of SCS CT are summarized in Fig. 13.

The surface net heat flux remains as the dominant process in driving the mixed layer temperature variability of the SCS CT on inter-annual time scale also. The positive and negative peaks in mixed layer temperature change coincide with strong anomalies in the surface heat flux. Interestingly, the horizontal advection has relatively important role in the mixed layer heat budget than the vertical processes on inter-annual time scale. The wintertime SST 
Fig. 13 Important processes responsible for the development of winter cold tongue in the SCS

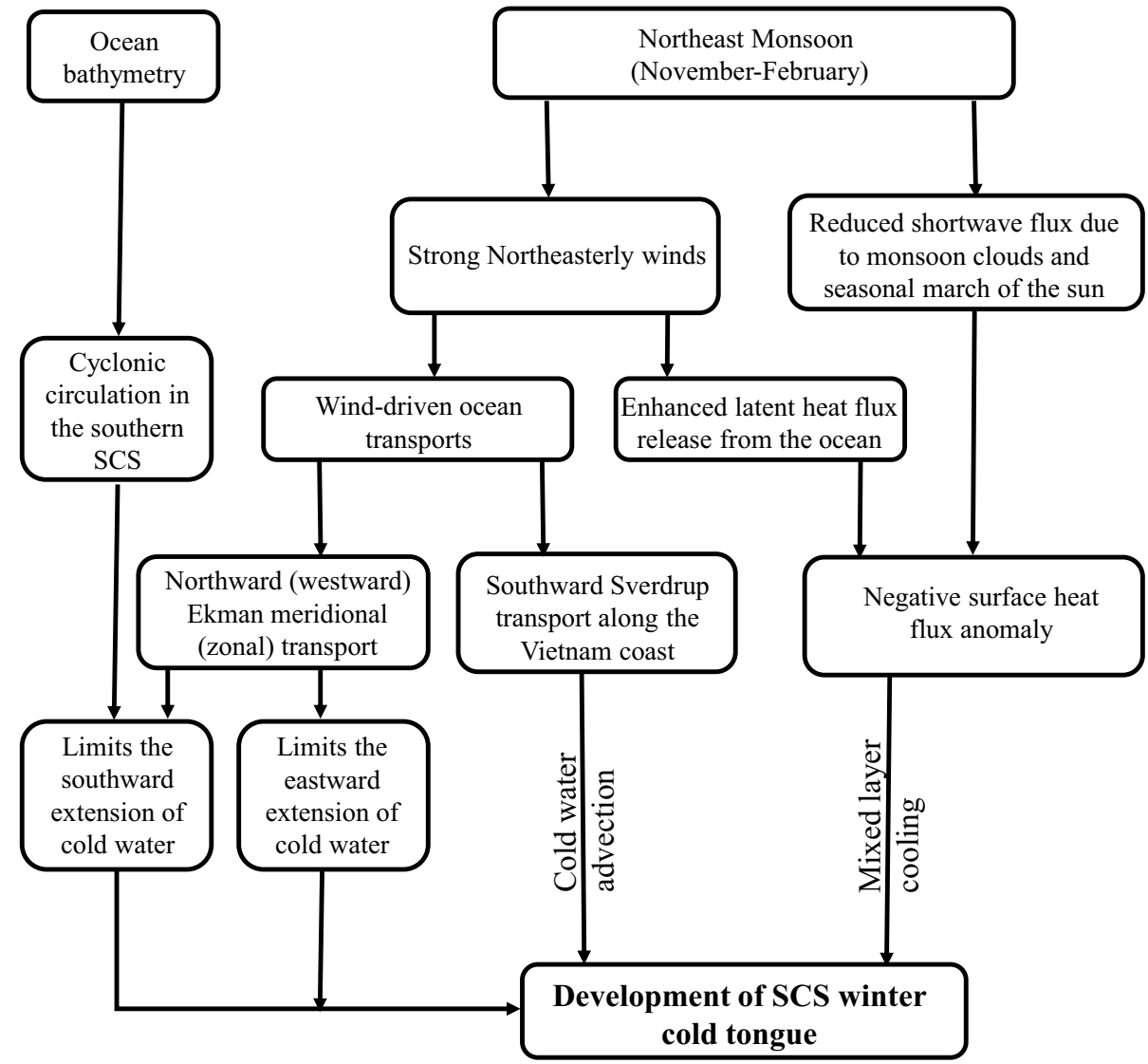

anomalies over the $\mathrm{CT}$ region are significantly linked to the Nino3 index. Most of the warming/cooling events in the SST anomalies coincide with the El Nino/La Nina phenomena in the Pacific Ocean.

In the present study, we have investigated the dynamical and thermodynamical processes responsible for the evolution of winter cold tongue in the SCS. The study helps to bring out the impact of oceanic as well as airsea coupled processes on the generation/growth of the SCS CT. The analyses revealed that the air-sea coupled processes have a dominant role in the evolution and interannual variability of SST over the CT region. To enhance our understanding of the SST cold anomaly in the SCS, more detailed studies using atmosphere-ocean coupled model simulations are necessary. Such studies become imperative given that SST over the CT has an active role in modulating the characteristics of East Asian winter monsoon (Koseki et al. 2013).

Acknowledgments This research was supported by the National Research Foundation Singapore through the Singapore MIT Alliance for Research and Technology's Centre for Environmental Sensing and Modeling interdisciplinary research program. The authors thank the reviewers and the editor for their constructive comments to improve the manuscript. We acknowledge NCDC-NOAA, ECMWF, UMD, NOC and Aviso for the AVHRR OISSTv2, ERA-interim,
SODA, NOC flux and Ssalto/Ducas geostrophic current field data sets respectively.

\section{References}

Alexander MA, Scott JD (2008) The role of Ekman Ocean heat transport in the Northern Hemisphere response to ENSO. J Clim 21:5688-5707

Alexander MA, Bladé I, Newman M, Lanzante JR, Lau N-C, Scott JD (2002) The atmospheric bridge: the influence of ENSO teleconnections on air-sea interaction over the global oceans. J Clim 15:2205-2231

Berry DI, Kent EC (2009) A new air-sea interaction gridded dataset from ICOADS with uncertainty estimates. Bull Am Meteorol Soc 90:645-656

Berry DI, Kent EC (2011) Air-sea fluxes from ICOADS: the construction of a new gridded dataset with uncertainty estimates. Int J Clim 31:987-1001

Carton JA, Giese BS (2008) A reanalysis of ocean climate using Simple Ocean Data Assimilation (SODA). Mon Wea Rev 136:2999-3017

Chao CY, Shaw PT, Wu SY (1996) El Nino modulations of the South China Sea circulation. Prog Oceanogr 38:51-93

Chen J-M, Chang C-P, Li T (2003) Annual cycle of the South China Sea surface temperature using the NCEP/NCAR reanalysis. J Meteorol Soc Jpn 81:879-884

Chu PC, Lu S, Chen Y (1997) Temporal and spatial variabilities of the South China Sea surface temperature anomaly. J Geophys Res 102: 20, 937-20, 955 
de Boyer MC, Vialard J, Shenoi SSC, Shankar D, Durand F, Ethé C, Madec G (2007) Simulated seasonal and interannual variability of mixed layer heat budget in the northern Indian Ocean. J Clim 20:3249-3268

Dee DP et al (2011) The ERA-Interim reanalysis: configuration and performance of the data assimilation system. Q J R Meteorol Soc 137:553-597

Fang G, Chen H, Wei Z, Wang Y, Wang X, Li C (2006) Trends and interannual variability of the South China Sea surface winds, surface height, and surface temperature in the recent decade. J Geophys Res 111:C11S16. doi:10.1029/2005JC003276

Huang E, Tian TJ, Steinke S (2011) Millennial-scale dynamics of the winter cold tongue in the southern South China Sea over the past $26 \mathrm{ka}$ and the East Asian winter monsoon. Quat Res 75(1): 196-204

Jerlov NG (1968) Optical oceanography. Elsevier, New York, p 194

Jhun J-G, Lee E-J (2004) A new East Asian winter monsoon index and associated characteristics of the winter monsoon. J Clim 17:711-726

Klein SA, Soden BJ, Lau N-C (1999) Remote sea surface variations during ENSO: evidence for a tropical atmospheric bridge. J Clim 12(4):917-932

Koseki S, Koh T-Y, Teo C-K (2013) Effects of the cold tongue in the South China Sea on the monsoon, diurnal cycle and rainfall in the Maritime Continent. Q J R Meteorol Soc 139:1566-1582

Levitus S (1987) Meridional Ekman heat fluxes for the world ocean and individual ocean basins. J Phys Oceanogr 17:1484-1492

Liu WT, Xie X (1999) Space based observations of the seasonal changes of the south Asian monsoon and oceanic responses. Geophys Res Lett 26:1473-1476

Liu Q, Jiang X, Xie S-P, Liu WT (2004) A gap in the Indo-Pacific warm pool over the South China Sea in boreal winter: seasonal development and interannual variability. J Geophys Res (Oceans) 109:C07012. doi:10.1029/2003JC002179

Liu Q, Jiang X, Xie S-P, Liu WT (2005) Sea surface wind and cold tongue over the winter South China Sea. IEEE Int 5:3294-3297

Liu Q-Y, Wang D, Wang X, Shu Y, Xie Q, Chen J (2014) Thermal variations in the South China Sea associated with the eastern and central Pacific El Niño events and their mechanisms. J Geophys Res (Oceans) 119:8955-8972
Madhusoodanan MS, Thompson B (2011) Decadal variability of the Arctic Ocean thermal structure. Ocean Dyn 61:873-880

Price JF, Weller RA, Schudlich RR (1987) Wind-driven ocean currents and Ekman transport. Science 238:1534-1538

Qu T (2001) Role of ocean dynamics in determining the mean seasonal cycle of the South China Sea surface temperature. J Geophys Res 106:6943-6955

Qu T, Du Y, Strachan J, Meyers G, Slingo J (2005) Sea surface temperature and its variability in the Indonesian region. Oceanography 18(4):50-61

Reynolds RW, Smith MTM, Liu C, Chelton DB, Casey KS, Schlax MG (2007) Daily high-resolution-blended analyses for sea surface temperature. J Clim 20:5473-5496

Shen S, Lau K-M (1995) Biennial oscillation associated with the East Asian summer monsoon and tropical sea surface temperature. J Meteorol Soc Jpn 73:105-124

Shenoi SSC, Shankar D, Shetye SR (2005) On the accuracy of the simple ocean data assimilation analysis for estimating heat budgets of the Near-Surface Arabian Sea and Bay of Bengal. J Phys Oceanogr 35:395-400

Stommel H (1965) The Gulf stream. University of Calif Press, Berkeley, p 248

Thompson B, Tkalich P (2014) Mixed layer thermodynamics of the Southern South China Sea. Clim Dyn 43:2061-2075

Tomita T, Yasunari T (1996) Role of the northeast winter monsoon on the biennial oscillation of the ENSO/monsoon system. J Meteorol Soc Jpn 74:399-413

Varikoden H, Samah AA, Babu CA (2010) The cold tongue in the South China Sea during boreal winter and its interaction with the atmosphere. Adv Atmos Sci 27(2):265-273

Vialard J, Delecluse P (1998) An OGCM study for the TOGA Decade. Part I: role of salinity in the physics of the Western Pacific Fresh Pool. J Phys Oceanogr 28:1071-1088

Wang C, Wang W, Wang D, Wang Q (2006) Interannual variability of the South China Sea associated with El Niño. J Geophys Res 111:C03023. doi:10.1029/2005JC003333

Wyrtki K (1961) Physical oceanography of Southeast Asian waters: scientific results of marine investigations of the South China Sea and Gulf of Thailand. Scripps Institution of Oceanography, NAGA Rep 2, La Jolla, p 195 